OAK RIDGE

- NATIONAL LABORATORY

MANAGED BY UT-BATTELLE

FOR THE DEPARTMENT OF ENERGY

\title{
Evaluation of 5-cm Centrifugal Contactor Hydraulic and Mass Transfer Performance for Caustic-Side Solvent Extraction of Cesium
}

\section{August 2001}

Prepared by

Joseph F. Birdwell, Jr., and Kimberly K. Anderson

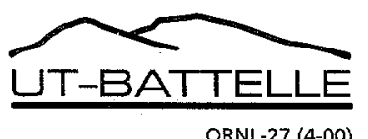




\section{DOCUMENT AVAILABILITY}

Reports produced after January 1, 1996 are generally available free via the U.S. Department of Energy (DOE) Information Bridge.

Web site http://www.osti.gov/bridge

Reports produced before January 1, 1996 may be purchased by members of the public from the following source.

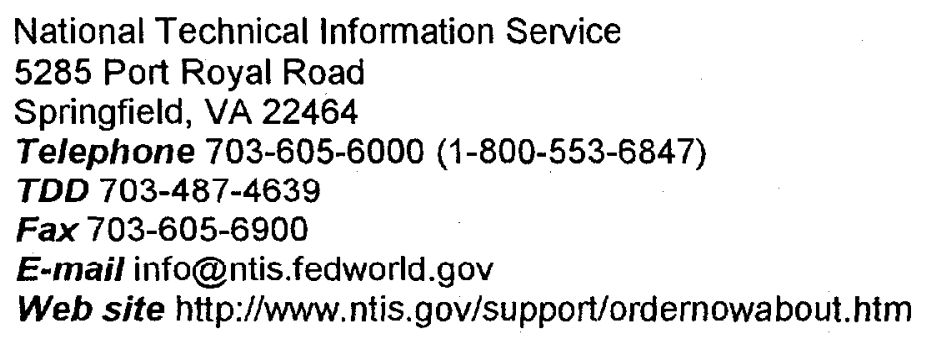

Reports are available to DOE employees, DOE contractors, Energy Technology Data Exchange (ETDE) representatives, and International Nuclear Information System (INIS) representatives from the following source.

Office of Scientific and Technical Information

P.O. Box 62

Oak Ridge, TN 37831

Telephone 865-576-8401

Fax 865-576-5728

E-mail reports@adonis.osti.gov

Web site http://www.osti.gov/contact.html

This report was prepared as an account of work sponsored by an agency of the United States Government. Neither the United States Government nor any agency thereof, nor any of their employees, makes any warranty, express or implied, or assumes any legal liability or responsibility for the accuracy, completeness, or usefulness of any information, apparatus, product, or process disclosed, or represents that its use would not infringe privately owned rights. Reference herein to any specific commercial product, process, or service by trade name trademark, manufacturer, or endorsement recommendation, or favoring by the United States Government or any agency thereof. The views and opinions of authors expressed herein do not necessarily state or reflect those of the United States Government of any agency thereof. 
ORNL/TM-2001/137

Chemical Technology Division

\title{
Evaluation of 5-cm Centrifugal Contactor Hydraulic and Mass Transfer Performance for Caustic-Side \\ Solvent Extraction of Cesium
}

\author{
Joseph F. Birdwell, Jr. ${ }^{*}$ \\ Kimberly K. Anderson

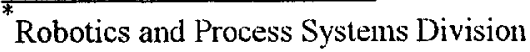

Date Published: August 2001

\author{
Prepared for the \\ DOE Office of Environmental Management \\ and the \\ Tanks Focus Area Salt Processing Project \\ DOE Office of Science and Technology, \\ Prepared by \\ OAK RIDGE NATIONAL LABORATORY \\ Oak Ridge, Tennessee 37831-6285 \\ managed by \\ UT-BATTELLE, LLC \\ for the \\ U.S. DEPARTMENT OF ENERGY \\ under contract DE-AC05-00OR22725.
}


1 


\section{CONTENTS}

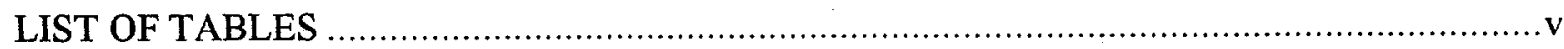

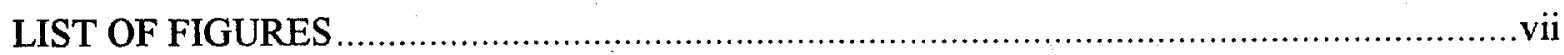

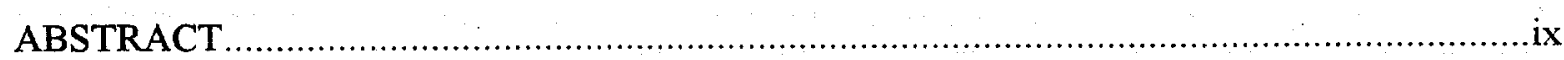

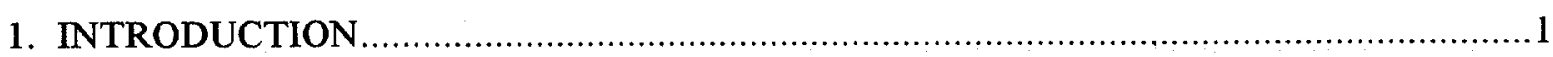

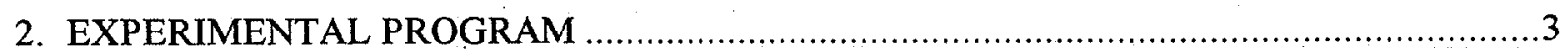

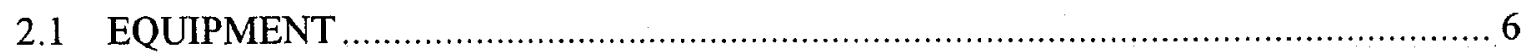

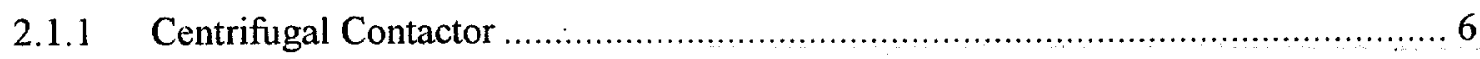

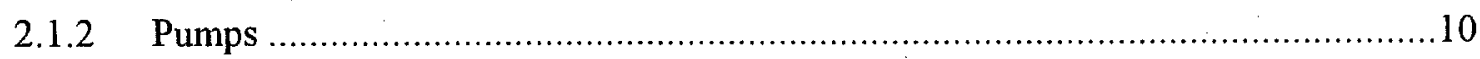

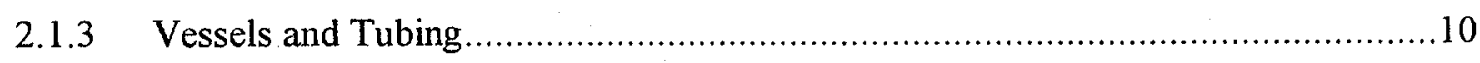

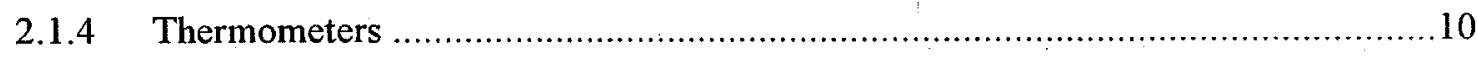

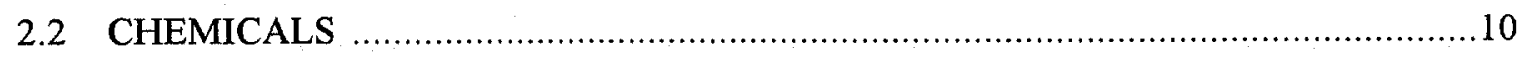

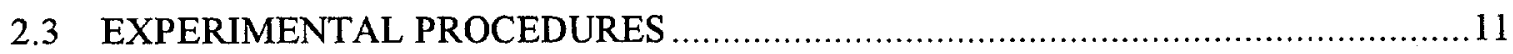

2.3.1 Determination of Dispersion Number................................................... 11

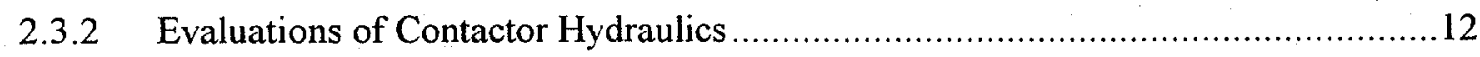

2.3.3 Mass Transfer Evaluations ................................................................. 13

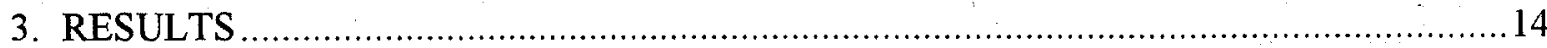

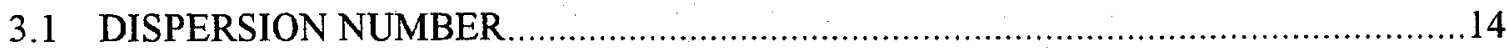

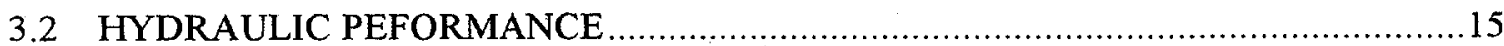

3.2.1 Extraction-Condition Throughput Performance .......................................... 15

3.2.2 Stripping-Condition Throughput Performance ............................................19

3.2.3 Summary of Throughput Determination and Hydraulic Performance Results ........20

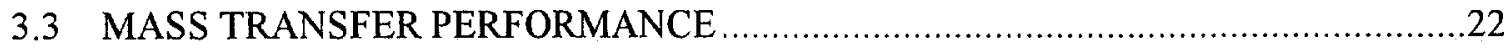

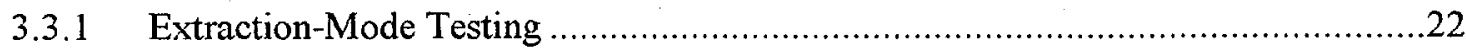

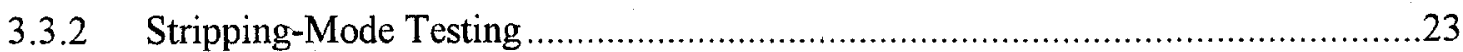

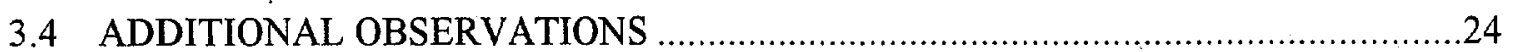

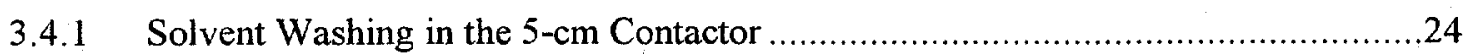

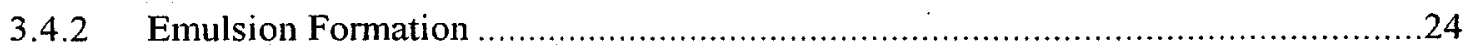

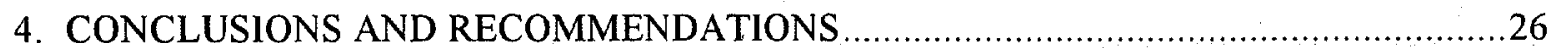

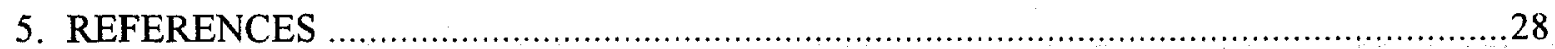




\section{LIST OF TABLES}

\section{Table}

Page

1

Composition of CSSX solvent

Key dimensions of CINC model V-2 (5-cm) centrifugal contactor ....................... 7

3 Results of disperson number determinations ............................................. 15

4 Single-stage extraction-mode mass transfer results using a modified centrifugal contactor

5 Single-stage stripping-mode mass transfer results using a modified centrifugal contactor. 


\section{LIST OF FIGURES}

Figure

2

3

4

5

6

7

Equipment configuration for contactor throughput determinations

Page

Equipment configuration for single-stage mass transfer testing ..................................5

Cross section of centrifugal contactor rotor with key dimensions indicated ................8

Photograph of contactor housing bottom as received from vendor ............................ 9

Photograph of contactor housing bottom after modification....................................

Throughput results for $5-\mathrm{cm}$ centrifugal contactor under extraction conditions ........16

Throughput results for $5-\mathrm{cm}$ centrifugal contactor under stripping conditions ..........17 


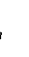

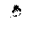

9 


\begin{abstract}
A test program has been conducted in which the use of pilot-scale centrifugal solvent extraction contactors for cesium removal from an alkaline waste stream has been successfully demonstrated. The program was designed specifically to evaluate the use of centrifugal contactors having 5 -cm-diam rotors for the removal of cesium from alkaline high-level waste (HLW) that was generated and is being stored at the U.S. Department of Energy's Savannah River Site (SRS). The removal of cesium from this waste is highly desirable because it will reduce the volume of waste that must be treated and disposed of as HLW.

The parameters applied in the test effort are those that have been established for the Caustic-Side Solvent Extraction (CSSX) process, a multistage extraction operation that has been designed by researchers at Oak Ridge National Laboratory (ORNL) and Argonne National Laboratory (ANL). In the CSSX process, cesium is extracted by calix(4)arene-bis-(tertoctylbenzo-crown-6), commonly referred to as BOBCalixC6. The extract is scrubbed with dilute $(0.05 \mathrm{M})$ nitric acid, both to remove coextracted elements (primarily potassium and sodium) and to adjust the $\mathrm{pH}$ of the extract to facilitate recovery of the cesium. The scrubbed solvent is contacted with $0.001 \mathrm{MHNO}_{3}$, which results in the stripping of the cesium from the solvent into the aqueous acid. The CSSX process flow rates have been established so to produce a cesium concentration in the strip effluent that is 12 to 15 times the concentration in the waste stream that enters the extraction section of the cascade.

Results from initial hydraulic testing of a commercially available $5-\mathrm{cm}$ contactor under CSSX conditions indicated that the mixing of feed solutions within the unit (which is critical to efficient solute transfer) was limited by a feature of the contactor that was designed to increase throughput and improve separation performance. In the design, phase separation is improved by reducing turbulence within the contactor. Subsequent to the initial hydraulic test, cesium transfer tests were performed using contactors arranged in both single-stage and multistage arrangements. Results of these tests confirmed that phase mixing within the contactor was inadequate.

In an effort to improve mixing within the contactor and thereby increase mass transfer efficiency, two minor modifications were made to a single contactor unit. One modification was the replacement of the bottom plate from the vendor-supplied contactor housing, which was equipped with curved (impeller-type) vanes, with a bottom assembly that had straight radial vanes. The latter configuration is the standard used in all existing ANL, ORNL, and SRS contactor designs. The second modification involved enlargement of the opening in the bottom of the rotor through which dispersion from the contactor mixing zone enters the rotor for separation. By increasing the rotor opening sufficiently, the rotor loses pumping efficiency to such an extent that accumulation of a hydrostatic head in the annular mixing zone is required for solution to be pumped through the contactor to the organic and aqueous discharge ports. By causing a volume of liquid to accumulate in the mixing zone, it is expected that phase mixing will be improved.

Following modification of a contactor, hydraulic testing was repeated to determine flow parameters to be applied in mass transfer testing using the modified device. As expected, test results indicated that the maximum throughputs that could bc achicved using the modified contactor under extraction and stripping conditions were lower than those obtained using the "asreceived" unit. However, phase separation performance within the reduced operating envelope was excellent. Most importantly, cesium transfer stage efficiencies were significantly improved over those obtained using the unmodified device and resulted in attainment of the target CSSX process decontamination factor of 40,000 when extrapolated to the baseline CSSX contactor cascade.
\end{abstract}




\section{INTRODUCTION}

A test program has been conducted to evaluate the hydraulic and mass transfer capabilities of a 5-cm centrifugal solvent extraction contactor for cesium recovery. The specific application on which the test protocol was based is the removal of cesium from alkaline highlevel waste (HLW) that has been generated and is stored at the U.S. Department of Energy (DOE) Savannah River Site (SRS).

Treatment and disposal of legacy HLW continues to be a high-priority focus of research and development efforts at DOE facilities that have been involved in reactor operation, nuclear weapons development and production, and nuclear fuel reprocessing. A basic concept applied in waste disposal and treatment efforts is the segregation of high-activity waste constituents from inventories in order to reduce the volume of material that must be disposed of under HLW restrictions. The ability to remove ${ }^{137} \mathrm{Cs}$ from these inventories is an essential component in efforts to reduce the amount of HLW repository space required for disposal of existing and projected materials.

To this end, researchers at the Oak Ridge National Laboratory (ORNL) have developed the compound calix(4)arene-bis-(tert-octylbenzo-crown-6), which has proven to be an effective and highly selective extractant for cesium, when combined with the components listed in Table 1. ${ }^{1}$ Use of this solvent in the multistage, Caustic-Side Solvent Extraction (CSSX) process is one of three candidate technologies being evaluated by the DOE for use in treatment of SRS HLW.

Bench-scale demonstrations of complete CSSX cascades consisting of 2-cm centrifugal contactors have been performed in a concurrent test program. Results of these tests have validated the CSSX flowsheet and have verified the ability to achieve the target cesium decontamination factor of 40,000 . The tests reported in this document serve as a bridge between the bench-scale cascade demonstrations and the pilot-scale tests that will be performed if the CSSX technology is selected for further development. In addition, the work reported is intended to verify that there are no equipment (i.e., contactor) limitations that will preclude removal of cesium from the SRS HLW to sufficiently low levels. Experience with centrifugal contactors indicates that phase separation and mass transfer results cannot necessarily be extrapolated from bench-scale contactors (i.e., 2-cm devices) to pilot- and full-scale devices. (Generally, an increase in mass transfer efficiency is observed in going from bench-scale to pilot- and full-scale contactors.) Results obtained at pilot scale can usually be extrapolated to full-scale contactors. 
Table 1. Composition of CSSX solvent

\begin{tabular}{lc}
\hline \multicolumn{1}{c}{ Component } & Concentration \\
\hline $\begin{array}{l}\text { calix(4)arene-bis-(lert-octylbenzo-crown-6) } \\
\text { (aka BOBCalixC6) }\end{array}$ & $0.01 \mathrm{M}$ \\
$\begin{array}{l}(2,2,3,3-T e t r a f l u o r o p r o p o x y)-3-(4-s e c-b u t y l \text { phenoxy)-2-propanol } \\
\text { (aka Cs-7SB) }\end{array}$ & $0.50 \mathrm{M}$ \\
Trioctylamine & $0.001 \mathrm{M}$ \\
Isopar ${ }^{\mathrm{L}} \mathrm{L}$ & Balance \\
\hline
\end{tabular}

The 5-cm contactor test program was conducted in five phases:

1. evaluation of phase separation by gravity settling under conditions present in the extraction, scrubbing, and stripping sections of the CSSX cascade;

2. evaluation of phase separation and determination of $5-\mathrm{cm}$ contactor throughput performance under extraction, scrubbing, and stripping conditions using "asreceived" contactors;

3. determinations of cesium transfer efficiency under extraction, scrubbing, and stripping conditions in both single-stage and multistage contactor configurations using the "as-received" units;

4. evaluation of phase separation and determinations of throughput under extraction and stripping conditions using a 5-cm contactor that had been modified to improve phase mixing; and

5. determination of cesium transfer efficiencies under extraction and stripping conditions in a single modified 5 - $\mathrm{cm}$ contactor.

Due to schedule constraints, contactors used in testing were procured from a commercial vendor and were fabricated according to one of the vendor's standard designs. The initial scope 
of the test program consisted of items 1,2 , and 3, with each step being a prerequisite to the succeeding work.

Observations of flow patterns within the contactor made during task 2 indicated that mixing of solutions in the as-received contactors was limited. This limitation was apparently due to a design feature that the vendor added specifically to increase contactor throughput and reduce mixing in the region between the rotor and the stationary housing. (The vendor's target application is the separation of cmulsions, including the recovery of crude and refined oils from spills into waterways.) Mass transfer results obtained from task 3 confirmed that phase mixing in the as-received contactors was inadequate. Consequently, the decision was made to modify a contactor to improve phase mixing and to repeat single-stage mass transfer tests using the modified device. Because the modifications affected contactor hydraulics, throughput determinations for the modified apparatus were necessary prior to performing mass transfer testing.

Only tasks 1, 4, and 5 are reported in this document; results from tasks 2 and 3 are presented only where needed for comparison. The decision to exclude discussion of tasks 2 and 3 from this report was based on the atypical configuration of the contactor used in these tests. Use of a contactor design in a CSSX process deployment that incorporates any feature intended to minimize phase mixing is contrary to the goal of the process. Furthermore, the specific atypical feature of the vendor-supplied devices - a housing bottom plate with curved vanes that are located in the space below the rotor-is a deviation from all prior contactor designs produced at Argonne National Laboratory (ANL), ORNL, and SRS. Therefore, to accurately compare results from the subject effort with those obtained in concurrent tests using 2-cm contactors, only results obtained using modified $5-\mathrm{cm}$ contactors should be considered.

\section{EXPERIMENTAL PROGRAM}

All throughput testing was performed using a single contactor configured for constant recycle of aqueous and organic solutions, as shown in Fig. 1. All mass transfer testing was performed using a single contactor configured for once-through processing of feed solutions, as indicated in Fig. 2.

Equipment used in determinations of dispersion numbers under gravity settling, which consisted of standard laboratory glassware and a stopwatch, is not described in any detail in this report. Detailed equipment descriptions presented in this section of the report are applicable to 


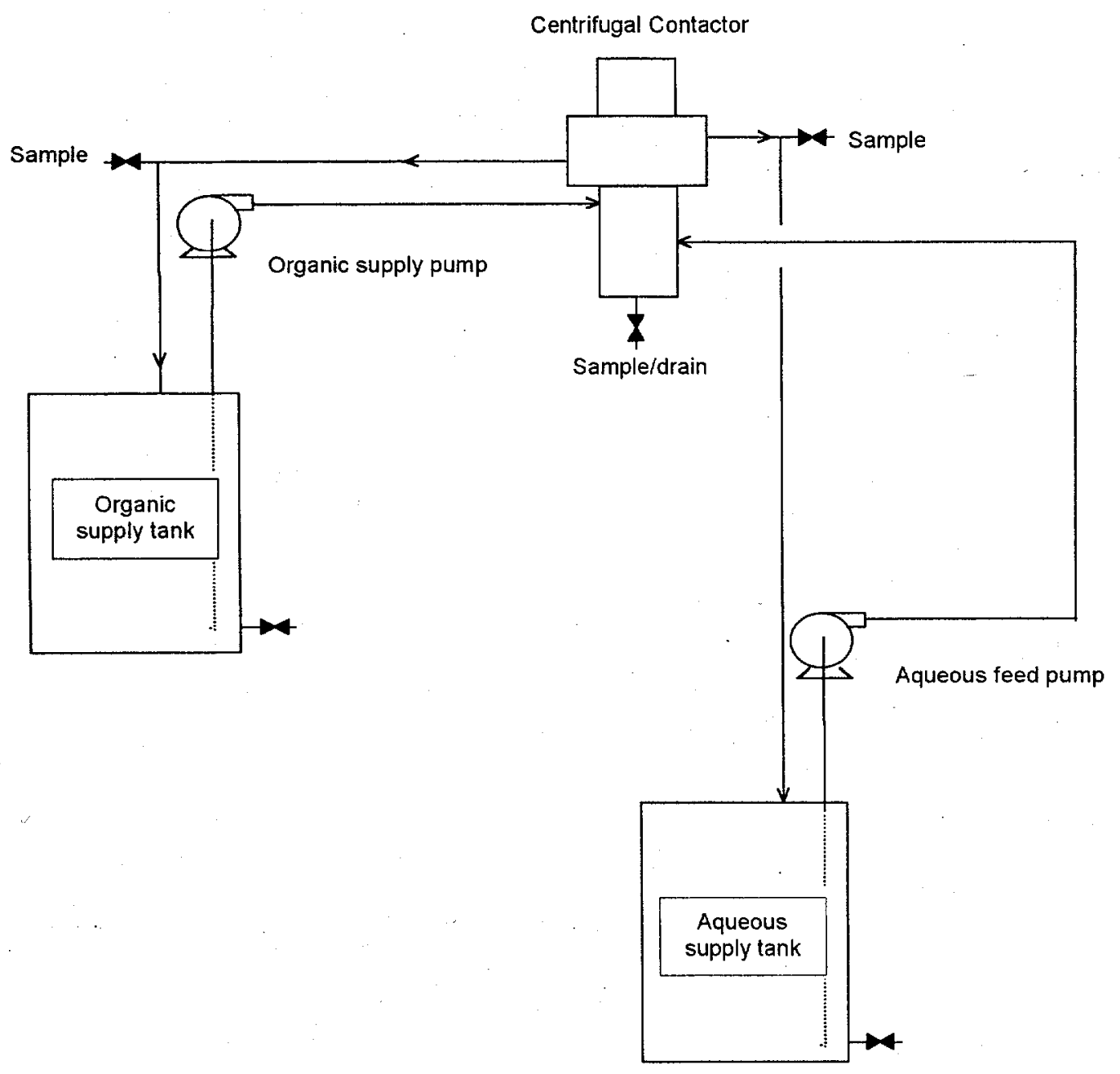

Fig. 1. Equipment configuration for contactor throughput determinations. 


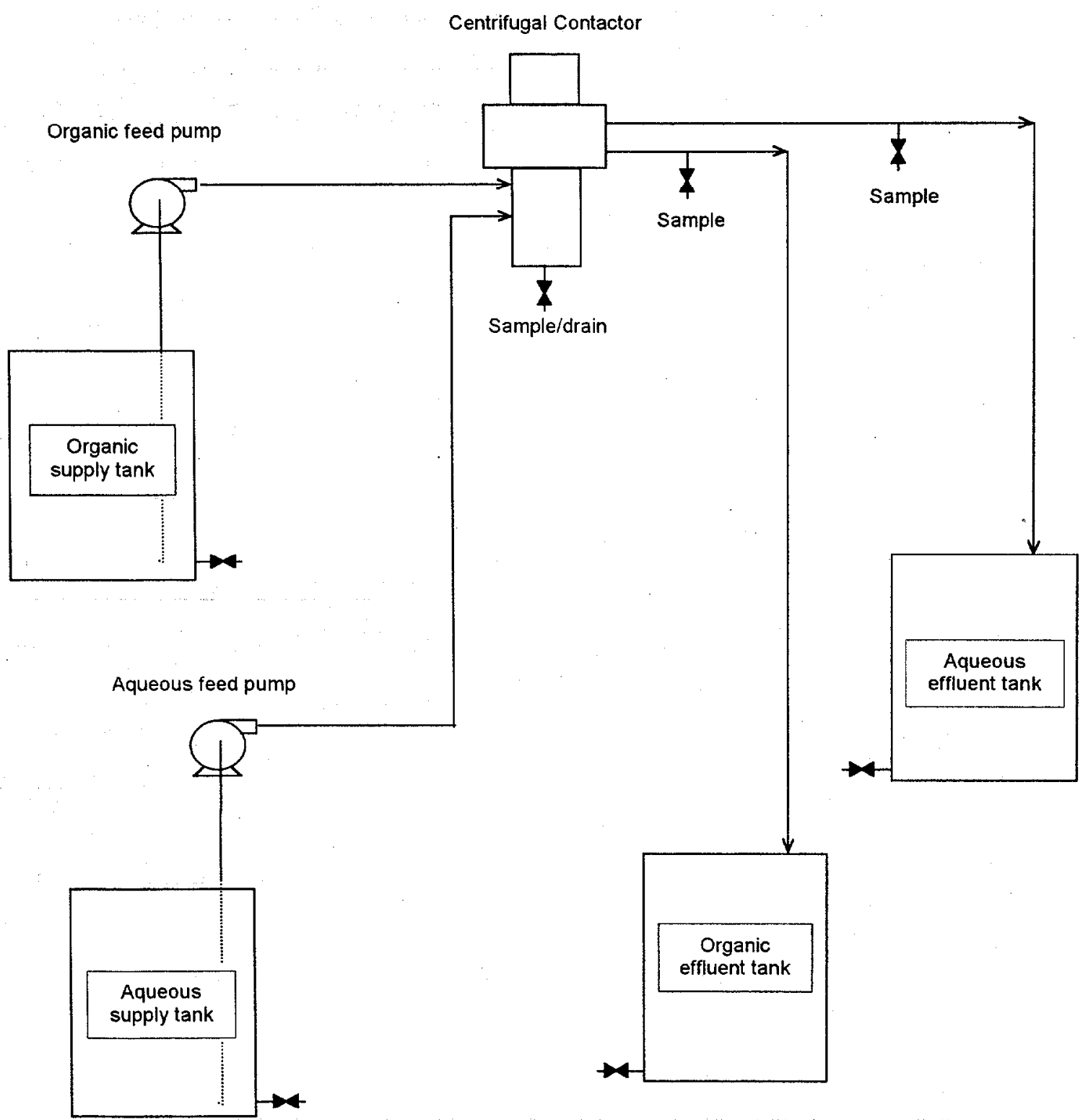

Fig. 2. Equipment configuration for single-stage mass transfer testing. 
testing performed using the modified contactor. Modified contactor tests utilized positivedisplacement metering pumps for transfer of solutions from feed tanks to the contactor. This equipment selection represents a change from preceding 5-cm CSSX tests (tasks 2 and 3 ) in which flows were delivered by means of centrifugal pumps and flow rates were monitored and controlled using rotameters with integral needle valves. The change in equipment, made to achieve greater feed stream flow precision, was implemented after difficulty was experienced maintaining steady flow rates at low-end values using the centrifugal pump/rotameter/valve scheme.

\subsection{EQUIPMENT}

\subsubsection{Centrifugal Contactor}

Centrifugal contactors used in testing were obtained from CINC, Inc. (Carson City, NV) as a standard-design item (model V-2). Of the four contactor units available for use in the subject test program, one had been used in work prior to the CSSX demonstration effort. That particular unit was equipped with a transparent window located in the mixing zone of the contactor housing. Because of concerns regarding mixing, this unit was used in all throughput and single-stage mass transfer testing to permit direct observation of flow behavior in the mixing zone.

The description of the contactors as " $5-\mathrm{cm}$ " refers to the outside diameter of the contactor rotor. All contactors were equipped with $110-\mathrm{V} \mathrm{AC}$ single-phase motors that were controlled by variable-frequency drives. Drive frequency was controllable in $0.1-\mathrm{Hz}$ increments, corresponding to speed increments of approximately $6 \mathrm{rpm}$. The maximum frequency of the drive controller was $100 \mathrm{~Hz}$, which corresponds to a nominal rotor speed of $6000 \mathrm{rpm}$. All wetted contactor components had been fabricated from $316 \mathrm{~L}$ stainless steel, TFE Teflon®, or TFE-encapsulated Viton ${ }^{\circledR}$. Contactor dimensions affecting throughput are listed in Table 2. A drawing of a contactor rotor in cross section with key dimensions indicated is presented in Fig. 3 .

All as-received contactors were equipped with rotor bottom plates as shown in Fig. 4. The vane configuration shown is exclusive to the manufacturer, ${ }^{2}$ who made the modification after obtaining rights to contactor technology from the DOE for the express purpose of designing and marketing centrifugal contactors as phase separators. The direction of the vane curvature matches the direction of rotation of the contactor in order to minimize disruption of streamlines as fluid moves from the annulus between the rotor and housing into the region below the rotor. 
Table 2. Key dimensions of CINC model V-2 $(5-\mathrm{cm})$ centrifugal contactor

\begin{tabular}{llcc}
\hline Designation & Description & Dimension (in.) & Dimension (mm) \\
& Aqueous weir radius & 0.4875 & 12.383 \\
RSA & Organic weir radius & 0.408 & 10.355 \\
RSO & Rotor inlet radius & 0.200 & $5.076^{b}$ \\
RT & Underflow radius & 0.875 & 22.208 \\
RU & Outside underflow radius & 0.938 & 23.807 \\
RC & Height of separating zone & 4.190 & 106.345 \\
BO & Height of aqueous channel & 0.400 & 10.152 \\
BA & Height between weirs & 0.668 & 16.954 \\
HAO & Rotor/housing gap radius & 0.250 & 6.345 \\
DRC & Angle between underflows & $38^{\circ}$ & \\
THETA & & & \\
\hline
\end{tabular}

${ }^{a}$ Unless designated otherwise.

${ }^{b}$ Dimension as received from the vendor. This dimension was increased to 9.61 $\mathrm{mm}$ to convert the contactor to the partially pumping mode.

After observing limited liquid holdup in the mixing zone of the as-received contactor and after obtaining unacceptable mass transfer results, modifications were made to improve phase mixing. First, a housing bottom cap with straight radial vanes was fabricated to replace the vendor-supplied component (refer to Fig. 5). Second, the opening in the bottom of the rotor through which the dispersed phases enter the rotor was enlarged from 5.076 to $9.610 \mathrm{~mm}$ to increase liquid holdup in the contactor mixing zone. Increased mixing zone holdup is obtained when the size of the rotor opening is increased sufficiently to change the contactor operating mode from fully to partially pumping.

In the fully pumping mode, the hydraulic force required to move fluids through the rotor is generated entirely by the rotor acting on the resident fluid. In this mode of operation, fluid flows from the mixing zone into the rotor and is immediately forced away from the opening so that a column of air is present coincident with the rotor's centerline and extending from the bottom of the rotor to the organic weir. The diameter of this air column just inside the rotor is greater than the diameter of the rotor opening. Because fluid entering the rotor moves immediately toward the wall, there is little, if any, back mixing of the liquids from the mixing zone into the separating zone of the contactor.

In the partially pumping mode, the contactor is operated so that the force generated by the rotor is not sufficient to "lift" solutions from the rotor inlet to the discharge ports. This condition can be induced by increasing the size of the rotor opening. When the rotor opening is enlarged beyond a certain value (depending on other contactor parameters), the mass inventory that can be supported at the bottom of the rotor is not adequate to produce the required lift (head) when accelerated by the turning of the rotor. Consequently, liquid accumulates in the rotor and the 


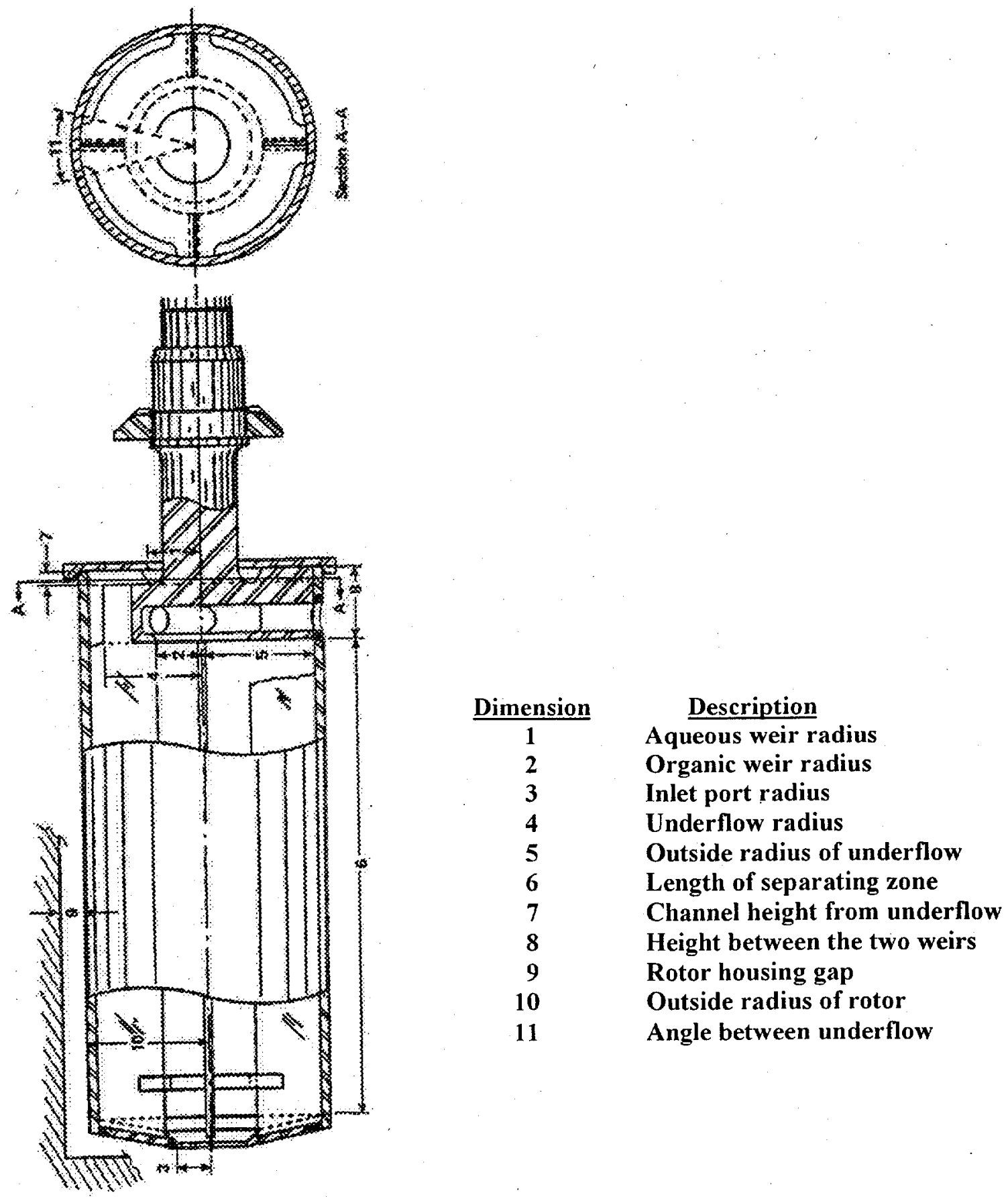

Fig. 3. Cross section of centrifugal contactor rotor with key dimensions indicated. 


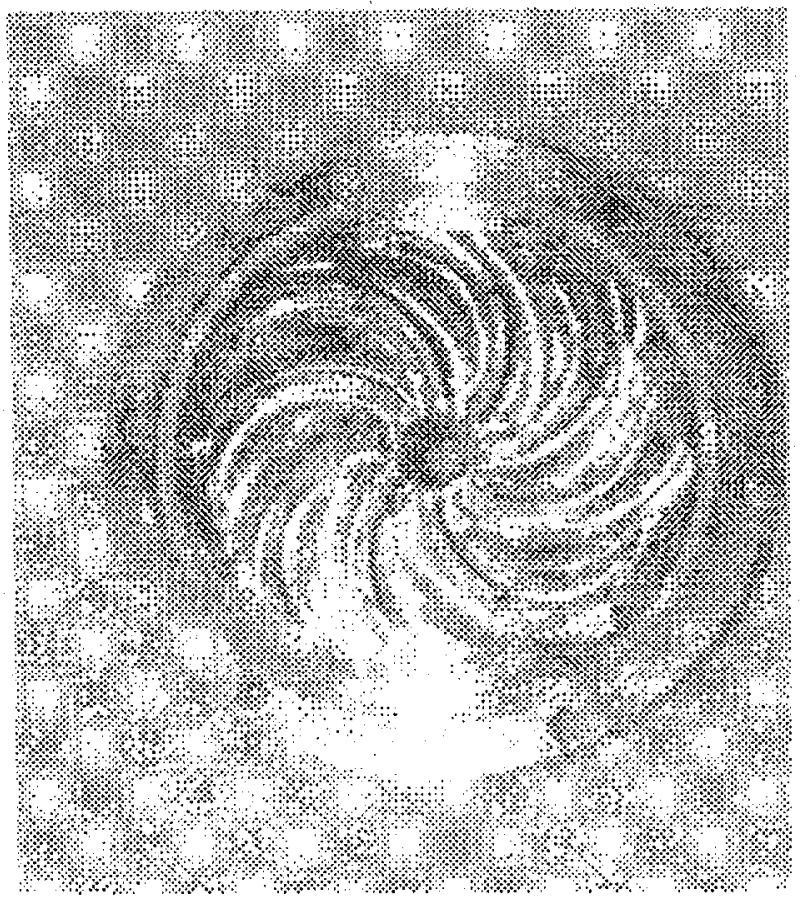

Fig. 4. Photograph of contactor housing bottom as received from vendor.

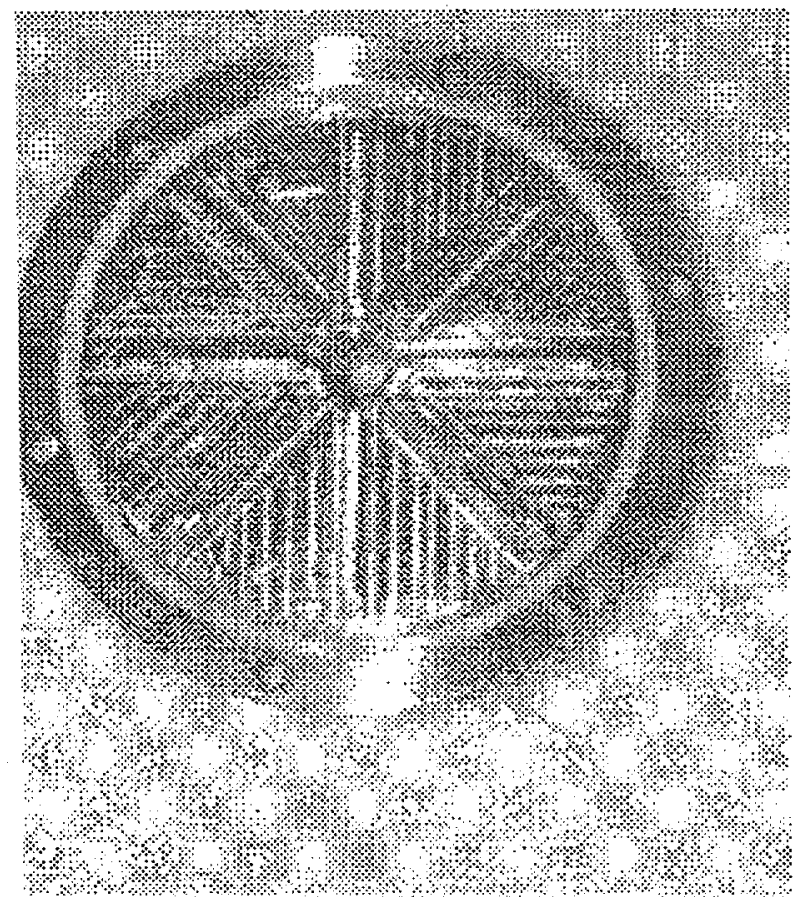

Fig. 5. Photograph of contactor housing bottom after modification. 
contactor annulus to the level necessary to compensate for reduced contactor pumping ability. In this mode of operation, there is no column of air inside the lower region of the rotor, and the lower section of the rotor becomes flooded. The demarcation between mixing and separating zones at the bottom of the rotor becomes somewhat indistinct, and the potential for back-mixing of solutions inside the bottom of the rotor and in the mixing zone increases. Mixing zone residence time is increased, potentially improving mass transfer efficiency. Conversely, partial flooding of the contactor reduces the effective separating zone height within the rotor, thereby reducing contactor throughput.

\subsubsection{Pumps}

All solution transfers were performed using piston-type metering pumps (Fluid Metering Inc., Model QV-2) with a maximum throughput of $1296 \mathrm{~mL} / \mathrm{min}$. The pump heads were equipped with 300 series stainless steel sleeves and ceramic pistons.

\subsubsection{Vessels and Tubing}

The vessels used to supply and receive solutions (15-L capacity high-density polyethylene tanks) were procured from VWR Scientific Products (Oak Ridge, TN, catalog no. 60464-043).

All tubing used during testing was PFA Teflon ${ }^{\circledR}$; all tubing fittings had been fabricated from $304 \mathrm{~L}$ stainless steel.

\subsubsection{Thermometers}

The temperatures of solutions collected from the contactor housing during mass transfer tests were determined using fast-response digital thermometers purchased from the Cole-Parmer Instrument Co. (Vernon Hills, IL, catalog no. P-90003-00). The thermometers are certified to have resolution to within $0.1^{\circ} \mathrm{C}$ up to $199.9^{\circ} \mathrm{C}$

\subsection{CHEMICALS}

The CSSX solvent is a blend of the organic materials listed in Table 1. The calixarene extractant was developed by researchers at ORNL specifically for the CSSX application. ${ }^{1}$ The solvent used in testing with the modified contactor had been used previously in throughput determinations and in mass transfer tests using as-received contactors. Prior to its use in the second series of throughput and mass transfer tests, the solvent was thrice stripped of cesium by contact with $0.001 \mathrm{MHNO}_{3}$, thrice washed with $0.01 \mathrm{M}$ sodium hydroxide, and thrice rinsed with 
demineralized water. Samples of the solvent were collected and were processed through a series of cesium extractions, acid scrubs, and dilute acid strips by ORNL Chemical and Analytical Sciences Division personnel to verify the effectiveness of the wash procedure. Cesium distribution results from the sample analysis were consistent with results obtained using virgin CSSX solvent.

Scrub $\left(0.05 \mathrm{MHNO}_{3}\right)$ and strip $\left(0.001 \mathrm{MHNO}_{3}\right)$ aqueous solutions were formulated using $0.10 \mathrm{~N} \mathrm{HNO}_{3}$ procured from J. T. Baker $\mathrm{Co}$. and diluted with water that had been deionized using a Barnstead Nanopure ${ }^{\circledR}$ filtration system. Sodium hydroxide solutions used to wash the solvent were formulated using a standard $0.1 \mathrm{~N}$ sodium hydroxide solution (ACS reagent grade, procured from the J. T. Baker Co.).

SRS waste supernatant simulant was formulated according to SRS procedure WSRC-RP2000-00361, Rev. 0, and had the composition listed in that document for "average" SRS supernatant simulant. ${ }^{3}$ The nominal cesium concentration in all simulant batches used in testing was $0.00014 M$.

\subsection{EXPERIMENTAL PROCEDURES}

\subsubsection{Determination of Dispersion Number}

Dispersion numbers were determined under extraction, scrubbing, and stripping conditions, with and without the presence of cesium. In all tests, phase volumes proportional to the flow rates of the solvent, scrub, and strip solutions in the CSSX flowsheet were placed into a $100-\mathrm{mL}$ graduated Pyrex(B) cylinder. The position of the interface was recorded. After a ground glass stopper was placed into the cylinder, the solutions were agitated for $20 \mathrm{~s}$; agitation was suspended for $10 \mathrm{~s}$ and then resumed for an additional $20 \mathrm{~s}$. (The method of intermittent agitation was selected based on published data indicating that it is a more effective means of dispersing immiscible phases than is continuous agitation. ${ }^{4}$ ) At the end of the second agitation, a stopwatch was started and the time required for the interface to return to its original position was recorded. The total height of the dispersion within the cylinder was measured. (In all cases, the dispersion band immediately after the second agitation period was the total liquid height in the cylinder.)

Dimensionless dispersion numbers were calculated according to the expression

$$
N_{D i}=\frac{1}{t_{b}} \sqrt{\frac{z}{g_{c}}},
$$


where $t_{b}$ is the break time in seconds, $z$ is the dispersion band height in feet, and $g_{c}$ is the gravitational constant $\left(32.172 \mathrm{ft} / \mathrm{s}^{2}\right)$.

\subsubsection{Evaluations of Contactor Hydraulics}

Hydraulic evaluations consisted primarily of determining the maximum solution throughput that could be processed without cross-phase contamination at a given rotor speed, organic/aqueous $(\mathrm{O} / \mathrm{A})$ solution pair, and $\mathrm{O} / \mathrm{A}$ flow ratio. In addition, the use of a contactor having a transparent window in the rotor housing at the mixing zone elevation facilitated visual observation of the mixing zone holdup.

Hydraulic studies were performed with the contactor configured for constant recycle, as shown in Fig. 1. Prior to contactor testing, the feed lines to the contactor were disconnected from the contactor and the feed pumps were calibrated. When the calibrations were completed, the feed lines were reconnected to the contactor housing and rotation was initiated at a predetermined speed. Once the target contactor speed was reached, the aqueous feed pump was turned on. Operation with aqueous flow only was continued until solution was observed in the aqueous discharge line, at which time the flow of organic solution was initiated.

After operation of the test loop for at least $3 \cdot \mathrm{min}$, samples of both effluent streams were collected and examined visually for cross-phase contamination. If no contamination was observed, flows were increased incrementally and proportionally, the system was allowed to regain steady state, and sampling was repeated. This process was continued until either of the effluent streams exhibited contamination with the opposing phase. The first observation of contamination of organic samples was generally the appearance of very small aqueous droplets in the bottom of the sample collection beaker. The onset of organic carryover in the aqueous effluent was indicated by the appearance of an organic film floating on top of the aqueous sample.

If contamination was found in either or both effluent streams, the flow rates were reduced proportionally, the system was allowed to stabilize, and sampling was repeated. The flow rate reduction procedure was repeated until no evidence of cross-phase contamination was found in either effluent stream.

$\Lambda \mathrm{fter}$ establishing the flow rate at which the onset of cross-phase contamination was observed, the contactor speed was reset and the throughput determination procedure was repeated. 


\subsubsection{Mass Transfer Evaluations}

Mass transfer determinations using the modified contactor were performed using a single device configured for once-through processing of feed solutions, as indicated in Fig. 2. Testing was limited to use of a single contactor to permit extended operation with a limited quantity of solvent, thereby increasing the likelihood that steady state would be reached prior to sampling. Results from multistage testing using the as-received contactors indicated that steady state was not achieved after a period of operation equal to three system residence times. The data obtained were insufficient to confirm that steady state was reached after five residence times.

Mass transfer testing with the modified contactor was performed under conditions present in the extraction and stripping sections of the CSSX cascade. Both extraction and stripping tests were performed at a rotor speed of $3600 \mathrm{rpm}$. Two sets of flow conditions were applied in each phase of testing. The first sets flow conditions that were applied in extraction and stripping tests were proportional to the relative flows in the extraction and stripping sections that are called for in the baseline CSSX full-cascade flowsheet.

Testing was initiated by starting the contactor, followed by initiation of aqueous solution feed. Once flow was observed in the aqueous discharge line, both the flow of organic and the experiment clock were started.

During extraction testing, samples were collected at 4 and 6 min after initiation of organic phase flow. Due to the decreased flow rates applied during strip testing, samples were collected 8 and $10 \mathrm{~min}$ after starting the organic-phase flow. Following collection of the second set of samples for each set of test conditions and with the rotor turning, approximately $50 \mathrm{~mL}$ of solution was drained from the contactor through a valve connected to the housing bottom. The temperature of this solution was measured immediately. Temperature measurements were not taken during the first sampling under each condition set to avoid upsetting the system between samplings.

Prior to the stripping test, the organic solution from the extraction test was twice scrubbed with $0.05 \mathrm{MHNO}_{3}$, using the modified contactor in order to adjust the $\mathrm{pH}$ of the extract in preparation for stripping. Following scrubbing, the contactor was dismantled, rinsed with demineralized water, and dried to prevent contamination of the stripping-condition test.

To determine the efficiency of the contactor, the collected samples were divided into two volumes. Aliquots of aqueous and organic effluents from each sampling were contacted in proportions equal to the relative flow rates. The samples were placed in sealed cuvettes. They were then submerged in a controlled temperature water bath that was set at the contactor solution temperature measured after the second sampling from each test condition. After equilibrating 
thermally for at least $15 \mathrm{~min}$, the cuvettes were agitated manually for two 20 -s intervals with an intermediate 10-s hold period. After agitation, the samples were placed back into the water bath and allowed to separate under gravity. After at least a $10-\mathrm{min}$ period of separation, the cuvettes were placed in a laboratory centrifuge to obtain complete phase separation. After centrifugation the cuvettes were placed back into the water bath for at least 5 min prior to collection of samples. Both equilibrated and as-collected samples were analyzed for cesium by inductively coupled plasma (ICP) mass spectrophotometry.

Mass transfer efficiencies were calculated using the Murphree definition based on the organic-phase concentrations,

$$
\eta=\frac{y-y_{i n}}{y_{e q}-y_{\text {in }}} \times 100
$$

where $y$ is the cesium concentration of the organic effluent, $y_{i n}$ is the inlet organic cesium concentration, and $y_{e q}$ is the cesium concentration of the organic effluent after equilibration.

\section{RESULTS}

\subsection{DISPERSION NUMBER}

Results of the dispersion number determinations are summarized in Table 3. As the table indicates, dispersion numbers were determined with and without the presence of cesium. The results indicate an increase in dispersion number with the addition of cesium under extraction conditions and decreases in $N_{D i}$ when cesium was present under scrubbing and stripping conditions. Because the minute concentrations of cesium present are unlikely to affect surface properties significantly, the differences are most likely the result of inherent inaccuracy in the determination of break time. (Break time determinations are prone to inaccuracy because of the qualitative nature of the end point.) In addition, during the reported test effort, it was found that break time was affected by the method of agitation (i.e., continuous versus interrupted), with the latter producing long separation times. More significant than the minor variations in $N_{D i}$ values is the fact that all values are sufficiently high to result in satisfactory phase separation in solvent extraction processes, based on prior experience. ${ }^{5}$ 
Table 3. Results of dispersion number determinations

\begin{tabular}{llll}
\hline Test condition & Dispersion height (ft) & Separation time (s) & Dispersion number \\
\hline Extraction w/o Cs & 0.52 & 114 & $1.10 \times 10^{-3}$ \\
Extraction w/ Cs & 0.52 & $85.3^{a}$ & $1.49 \times 10^{-3}$ \\
Scrubbing w/o Cs & 0.23 & 80 & $1.05 \times 10^{-3}$ \\
Scrubbing w/ Cs & 0.42 & 120 & $9.64 \times 10^{-4}$ \\
Stripping w/o Cs & 0.17 & 60 & $1.34 \times 10^{-3}$ \\
Stripping w/Cs & 0.41 & $97.5^{\mathrm{a}}$ & $1.15 \times 10^{-3}$ \\
\hline
\end{tabular}

${ }^{a}$ Average of replicate determinations.

\subsection{HYDRAULIC PERFORMANCE}

For comparison purposes, the results of extraction- and stripping-condition throughput tests using both the as-received and modified $5-\mathrm{cm}$ contactor are presented in Figs. 6 and 7 , respectively. It should be noted that, using an as-received contactor, a significant liquid level could be maintained only at lower operating speeds $(<4200 \mathrm{rpm})$. Using this device, minimal mixing heights could be achieved at higher speeds (up to $6000 \mathrm{rpm}$ ), but such heights could be maintained only over very narrow flow ranges without incurring unacceptable phase separation. The range of flow rates that produced an observable, steady liquid height in the mixing zone of the as-received contactors increased as the rotor speed was reduced. However, this range remained too narrow to permit significant flexibility in processing rate.

\subsubsection{Extraction-Condition Throughput Performance}

Initial throughput evaluations were performed using the modified contactor with a 0.875 in.-diam aqueous weir plate installed. The same weir diameter had been used in throughput testing performed using an unmodified contactor. As expected, use of the partially pumping rotor resulted in a significant increase in the liquid height within the contactor mixing zone at all flow and speed conditions. At higher rotor speeds, the liquid in the mixing zone was generally opaque but exhibited some areas of translucence where the rotor could be seen through the observation window. At lower speeds, the liquid holdup took on an appearance of uniform opacity such that the rotor could not be seen below the upper liquid surface in the mixing zone. 


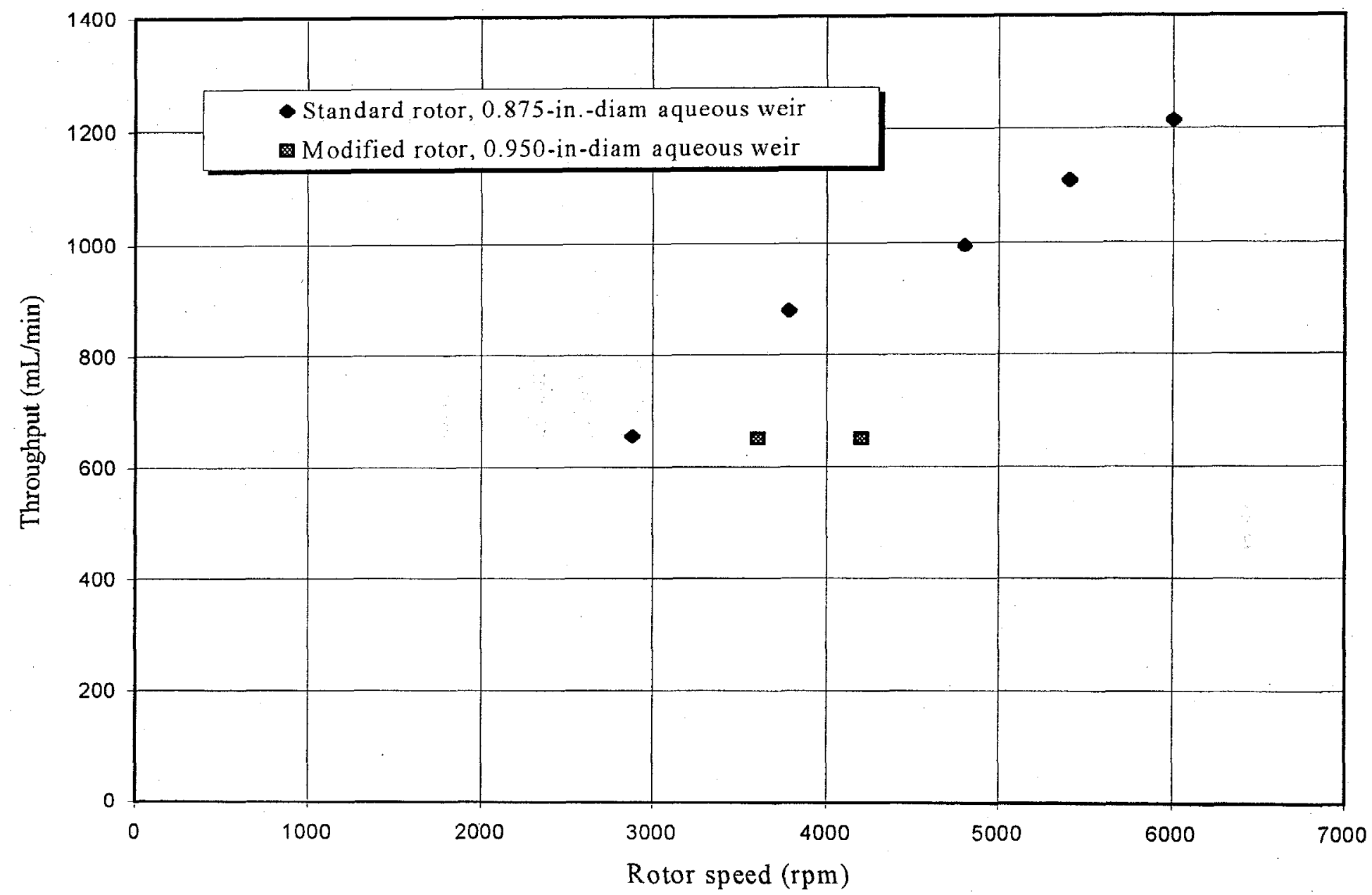

Fig. 6. Throughput results for 5-cm centrifugal contactor under extraction conditions. 


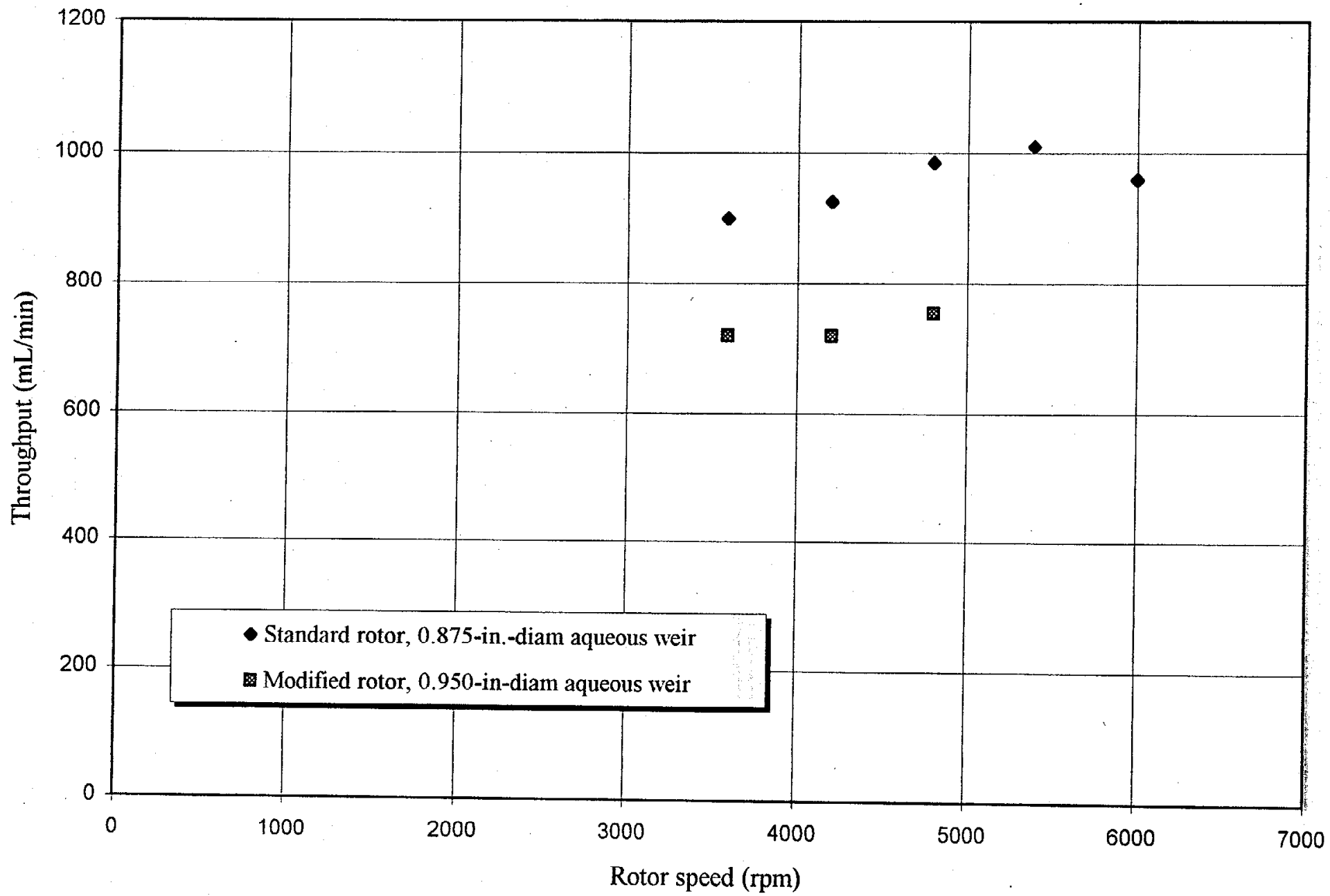

Fig. 7. Throughput results for 5-cm centrifugal contactor under stripping conditions. 
The first evaluation using the modified contactor was performed at $6000 \mathrm{rpm}$ with organic and aqueous phase flow rates of 80 and $235 \mathrm{~mL} / \mathrm{min}$, respectively. With aqueous-only feed, the liquid height in the mixing zonc was about onc-third the distance between the rotor bottom and the organic collection ring. Shortly after organic flow was established liquid was observed over the entire height of the mixing zone that was visible through the housing window. No foaming was observed in either of the discharge lines from the contactor. A single droplet of aqueous carryover was found in a sample of organic effluent; there was no organic-phase carryover in the aqueous effluent. With the rotor turning at $6000 \mathrm{rpm}$, the flow rates of organic and aqueous phases were reduced first to $V_{\mathrm{O}}=75 \mathrm{~mL} / \mathrm{min}$ and $V_{\mathrm{A}}=215 \mathrm{~mL} / \mathrm{min}$, then to $V_{\mathrm{O}}=62$ $\mathrm{mL} / \mathrm{min}$ and $V_{\mathrm{A}}=181 \mathrm{~mL} / \mathrm{min}$. Aqueous effluent samples collected at both conditions showed no evidence of contamination with the organic solvent. Droplets of aqueous contamination were found in samples of organic effluent collected under both sets of conditions, and successive organic-phase samples collected at each condition showed gradual increases in the level of contamination.

Subsequently, effluent samples were collected at a range of flow conditions and at rotor speeds ranging from 2400 to $6000 \mathrm{rpm}$. In all cases, the aqueous effluent was found to be free of organic-phase carryover. However, in all cases there was evidence of aqueous-phase contamination in the organic effluent. The degree of contamination ranged from a single aqueous drop (diameter of $\approx 1 \mathrm{~mm}$ ) in approximately $50 \mathrm{~mL}$ of organic solution to $>10 \%$ carryover.

In an effort to shift the phase boundary inside the rotor radially outward (and increase the residence time of the organic phase within the separating zone), the aqueous weir plate was replaced with one having a diameter of 0.950 in. After replacing the weir plate, contactor operation was resumed at a rotor speed of $3600 \mathrm{rpm}$ with aqueous and organic phase flows of 375 and $115 \mathrm{~mL} / \mathrm{min}$, respectively. The test loop was operated for approximately $3 \mathrm{~min}$ prior to sampling to attain steady state. No cross-phase contamination was seen in samples collected from the two effluent streams. All subsequent throughput evaluations using the partially pumping rotor were performed with an aqueous weir diameter of 0.950 in.

At $3600 \mathrm{rpm}$, flow rates were increased to $160 \mathrm{~mL} / \mathrm{min}$ of solvent and $490 \mathrm{~mL} / \mathrm{min}$ of aqueous solution with no indication of effluent contamination. When the flows were increased proportionally above these values, aqueous contamination of the organic effluent was observed. Acceptable separation performance was reestablished by returning flow rates to $V_{\mathrm{A}}=490 \mathrm{~mL} / \mathrm{min}$ and $V_{\mathrm{O}}=160 \mathrm{~mL} / \mathrm{min}$. 
Testing at $4200 \mathrm{rpm}$ was initiated at aqueous and organic flow rates of 490 and $160 \mathrm{~mL} / \mathrm{min}$, respectively. Effluent samples collected after the system was allowed to reach steady state were free of cross-phase contamination. Attempts were made to operate at flow rates that were increased proportionally from the initial values. In all cases, aqueous carryover was found in organic effluent samples. As occurred at the 3600-rpm rotor speed, good phase separation was reestablished when the flows were reset to $V_{\mathrm{A}}=490$ and $V_{\mathrm{O}}=160$.

Attempts were made to operate the contactor at a rotor speed of $4800 \mathrm{rpm}$, using flow conditions that had produced good separation results at both 3600 and $4200 \mathrm{rpm}$. In all cases, aqueous contamination was observed in organic effluent samples.

In an attempt to reestablish acceptable separation performance (i.e., clear the contactor), the flows to the device were terminated and the rotor speed was increased to $6000 \mathrm{rpm}$. When flow from the contactor stopped, the contactor motor was turned off and the rotor and rotor housing were drained. To verify previous results, the contactor was operated at $3600 \mathrm{rpm}$ with $V_{\mathrm{A}}=375 \mathrm{~mL} / \mathrm{min}$ and $V_{\mathrm{O}}=115 \mathrm{~mL} / \mathrm{min}$. Both effluent streams were free of opposing-phase carryover. The rotor speed was then increased to $4200 \mathrm{rpm}$ and the maximum flow conditions established earlier at this speed $\left(V_{\mathrm{A}}=490 \mathrm{~mL} / \mathrm{min}\right.$ and $\left.V_{\mathrm{O}}=160 \mathrm{~mL} / \mathrm{min}\right)$ were successfully verified. Another attempt was made to separate the phases at a rotor speed of $4800 \mathrm{rpm}$ with $V_{\mathrm{A}}$ $=490 \mathrm{~mL} / \mathrm{min}$ and $V_{\mathrm{O}}=160 \mathrm{~mL} / \mathrm{min}$. As had occurred previously, significant carryover of

aqueous solution $(>1 \%)$ was seen in the organic discharge stream. Subsequent sample collections at reduced flow conditions $\left(V_{\mathrm{A}}=260 \mathrm{~mL} / \mathrm{min}\right.$ and $\left.V_{\mathrm{O}}=95 \mathrm{~mL} / \mathrm{min}\right)$ resulted in findings of continued aqueous-phase carryover in the organic effluent from the contactor. Carryover at these flow conditions was eliminated after stopping the contactor, draining the rotor and housing, and restarting at $3000 \mathrm{rpm}$.

Finally, to verify operational stability as a prerequisite for follow-on mass transfer testing, the contactor was operated at a rotor speed of $3600 \mathrm{rpm}$ for $20 \mathrm{~min}$ at $V_{\mathrm{A}}=490 \mathrm{~mL} / \mathrm{min}$ and $V_{\mathrm{O}}=160 \mathrm{~mL} / \mathrm{min}$. Acceptable performance was maintained throughout the test period under these conditions.

\subsubsection{Stripping Condition Throughput Performance}

Because of to the similarities between scrubbing and stripping conditions in the CSSX flowsheet and because follow-on mass transfer testing was to be performed only under extraction and stripping conditions, throughput testing of the modified contactor was not performed under scrubbing conditions. Prior to stripping-mode throughput tests, the system was rinsed with deionized water. A sample of the rinse water used was determined to have a $\mathrm{pH}$ value of 
approximately 10. After the water rinse, the system was flushed with CSSX scrub solution (i.e., $0.05 \mathrm{MHNO}_{3}$ ). After the system was rinsed for about $6 \mathrm{~min}$, the aqueous discharge stream was determined to have a $\mathrm{pH}$ of approximately 3 . At this point, rinsing was terminated and the aqueous solution in the test loop was replaced with $\operatorname{CSSX}$ strip acid $\left(0.001 M \mathrm{HNO}_{3}\right)$.

No entrainment was found in either effluent stream when the contactor was operated at $3600 \mathrm{rpm}$ with flow conditions $V_{\mathrm{A}}=90 \mathrm{~mL} / \mathrm{min}$ and $V_{\mathrm{O}}=450 \mathrm{~mL} / \mathrm{min}$. No cross-phase contamination was observed at flow rates up to $V_{\mathrm{A}}=120 \mathrm{~mL} / \mathrm{min}$ and $V_{\mathrm{O}}=600 \mathrm{~mL} / \mathrm{min}$. However, at $V_{\mathrm{A}}=130 \mathrm{~mL} / \mathrm{min}$ and $V_{\mathrm{O}}=650 \mathrm{~mL} / \mathrm{min}$, an organic film appeared on the surface of the samples of aqueous effluent. The organic film became more apparent when the flows were increased to $V_{\mathrm{A}}=140 \mathrm{~mL} / \mathrm{min}$ and $V_{\mathrm{O}}=700 \mathrm{~mL} / \mathrm{min}$.

To test the ability of the partially pumping rotor to recover from undesirable operating conditions, the organic flow to the contactor was terminated. Aqueous samples collected for up to $5 \mathrm{~min}$ after termination of the solvent flow retained an organic film layer.

At $4200 \mathrm{rpm}$ with flow rates $V_{\mathrm{A}}=120 \mathrm{~mL} / \mathrm{min}$ and $V_{\mathrm{O}}=600 \mathrm{~mL} / \mathrm{min}$, both the aqueous and organic effluent streams were free of contamination. As was the case at $3600 \mathrm{rpm}$, an organic film appeared on the surface of aqueous effluent samples collected at tlow rate conditions $V_{\mathrm{A}}=130 \mathrm{~mL} / \mathrm{min}$ and $V_{\mathrm{O}}=650 \mathrm{~mL} / \mathrm{min}$.

To clear the aqueous contactor flow path of solvent prior to testing at $4800 \mathrm{rpm}$, the flow of organic to the contactor was suspended while contactor operation was continued for approximately $3 \mathrm{~min}$. The rotor speed was increased to $4800 \mathrm{rpm}$, and flow rates were set at $V_{\mathrm{A}}=$ $120 \mathrm{~mL} / \mathrm{min}$ and $V_{\mathrm{O}}=600 \mathrm{~mL} / \mathrm{min}$. No contamination was observed in samples collected from the two effluent streams. The same result was obtained after increasing the flow rates to $V_{\mathrm{A}}=125 \mathrm{~mL} / \mathrm{min}$ and $V_{\mathrm{O}}=630 \mathrm{~mL} / \mathrm{min}$. An organic film appeared on the surface of aqueous effluent samples collected after the flows had been increased to $V_{\mathrm{A}}=130 \mathrm{~mL} / \mathrm{min}$ and $V_{\mathrm{O}}=650 \mathrm{~mL} / \mathrm{min}$. Recovery was accomplished by suspending the flow of solvent to the contactor.

\subsubsection{Summary of Throughput Determination and Hydraulic Performance Results}

Results of the throughput testing using the CINC $5-\mathrm{cm}$ contactor indicale that the phase separation aspects of the device perform very well in the CSSX application. However, as the data in Figs. 6 and 7 indicate, throughput capacity was significantly reduced when the partially pumping rotor was used.

Using the fully pumping (as-received) rotor, the primary limitation to increased throughput was the accumulation of foam in the organic discharge line, particularly under 
extraction and scrubbing conditions. Observations made during testing with this rotor indicated that the foam consists entirely of the solvent and is generated in the upper region of the contactor-possibly by the impact of solvent against the wall of the organic collection trough after it exits the rotor. Reducing flow through the contactor was found to eliminate foaming. It was also found determined that maximum flows could be increased without foam backup from the organic discharge line into the contactor mixing zone by sloping the line downward from the contactor outlet connection.

Due to a reduced tendency toward foaming, phase separation performance using the asreceived contactor under stripping conditions was more robust than indicated for extraction and scrubbing conditions. Throughput capacities using this unit under stripping conditions were consistently higher than capacities under scrubbing conditions. A review of test observations indicates that the limiting factor preventing scrubbing-mode operation under conditions that produced acceptable stripping-mode phase separation was the appearance and accumulation of organic-phase foam.

Extraction-mode throughput testing using a partially pumping rotor was initially plagued by aqueous-phase contamination in the organic effluent. Numerous attempts to obtain acceptable phase separation by changing the rotor speed and the solution feed rates were unsuccessful. Once it became apparent that the residence time of the organic phase within the separating zone was insufficient (probably due to the loss of effective separation height resulting from partial-pumping operation), an aqueous weir with a larger opening was installed. This modification caused a shift in the phase boundary within the rotor away from the organic weir and successfully eliminated organic effluent contamination under many flow conditions.

Excellent mixing zone heights were observed under all flow conditions applied during throughput tests using the partially pumping rotor. As a result of the modification, mass transfer operations could be performed at very low flow rates without apparent loss of mixing capability. As expected, flow capacities were significantly reduced in the partially pumping condition. Two significant differences between results obtained with a fully pumping rotor and those achieved with a partially pumping device are apparent. First, the chief limiting factor under extraction conditions with a partially pumping rotor appears to be phase scparation within the rotor. In the fully pumping mode, extraction throughput was usually limited by foam formation outside the rotor. Second, recovery from unfavorable flow and speed conditions using the partially pumping rotor was slow when attempted by resetting flows and speeds to proven values. More rapid recovery required termination of the organic flow. After extreme upset conditions, recovery was accomplished by stopping all flows and draining the contactor. This process was necessary 
because of the extremely long times required to reestablish acceptable phase separation under continuous contactor operation.

Under extraction and stripping conditions, the fully pumping (i.e., as-received) contactor exhibited both greater processing capacity and greater responsiveness to increased rotor speed. The first result is expected because the loss of separation height resulting from partial-pumping operation significantly affects the ability of the contactor to provide adequate phase separation as throughput increases. In addition, reduced pumping efficiency in the partially pumping contactor limits the extent to which increased rotor speed can affect throughput.

\subsection{MASS TRANSFER PERFORMANCE}

As noted in Sect. 1, cesium transfer efficiencies obtained in tests using as-received centrifugal contactors were below expected values and would not produce the degree of waste decontamination required in the proposed SRS application. Observations made during both throughput and mass transfer tests indicated a high probability that low mass transfer efficiencies were the result of poor mass transfer conditions (i.e., phase mixing) and were not due to process chemistry limitations. To offset the poor mixing performance observed in previous tests, the contactor modifications described earlier in this report were made.

Because cesium mass transfer in the scrubbing section of the CSSX cascade is not a process performance metric, mass transfer testing using the modified contactor was performed under extraction and stripping conditions only. However, because of the adverse effect that hydroxide carryover from extraction to stripping can have on cesium distribution during stripping, the extract was scrubbed with the standard CSSX scrub solution and $\mathrm{pH}$ adjustment was verified prior to performance of the stripping test.

\subsubsection{Extraction-Mode Testing}

Aqueous feed for extraction-mode testing was produced by combining SRS waste sinulant with CSSX scrub solution in the proportion 20.1:1.33, which reflects flow conditions in the baseline CSSX flowsheet. Solvent used in mass transfer testing had been recovered from previous mass transfer and hydraulic tests. The recovered solvent had been stripped three times with $0.001 \mathrm{MHNO}_{3}$, washed three times with $0.01 \mathrm{M} \mathrm{NaOH}$, and rinsed three times with deionized water. Phase separation and cesium extraction performance of the washed solvent were verified in laboratory-scale tests prior to its use in the supplemental test program. All system components were thoroughly cleaned prior to mass transfer testing. 
Contactor operation was initiated at $3600 \mathrm{rpm}$. Flow of aqueous feed solution was started at a rate of $484 \mathrm{~mL} / \mathrm{min}$. When aqueous solution began to exit the contactor, solvent flow was initiated at $150 \mathrm{~mL} / \mathrm{min}$. Samples of the effluent streams were collected after 4 min of operation and again after 6 min of operation. After the second sample set was collected, feed flows were stopped and the contactor was partially drained with the contactor still operating. The temperature of the solution collected was measured and recorded.

The metering pumps used to deliver the feed streams were reset to provide flows of $V_{\mathrm{A}}=306 \mathrm{~mL} / \mathrm{min}$ and $V_{\mathrm{O}}=95 \mathrm{~mL} / \mathrm{min}$. Flows of aqueous and organic feed solutions were reestablished in the same manner as before. Samples of both effluent streams were collected $8 \mathrm{~min}$ after resumption of solvent flow and again after $10 \mathrm{~min}$ of testing. As before, after the second sampling, the flows were stopped, the contactor housing was partially drained, and the temperature of the solution was measured and recorded.

Test results of extraction-mode testing are summarized in Table 4. The results indicate highly efficient transfer of cesium under both sets of flow conditions applied during testing.

An attempt was made to isolate the effects of the two contactor modifications-partial pumping rotor and housing vane design-on mass transfer performance. In order to separate these variables, it was necessary to operate a partially pumping rotor with the as-received vane configuration and to test a straight-vane housing bottom with a fully pumping rotor. Because of changes in contactor designs, the straight-vane bottom fabricated for use with the partially pumping rotor could not be used with a new fully pumping rotor. The newer rotor design is slightly shorter than the earlier version. The resulting increase in the gap between the bottom vanes from the older contactor design and the bottom of the newer-design rotor allows vortex formation below the rotor to the extent that the vane/rotor combination will not pump. Consequently, attempts to isolate the effects of configuration on mass transfer were abandoned.

\subsubsection{Stripping-Mode Testing}

Due to the adverse effect that hydroxide ion carryover has on cesium stripping efficiency, the extract produced in the supplemental extraction-mode test was contacted twice with $0.05 \mathrm{M}$ $\mathrm{HNO}_{3}$ using the modified contactor operating at $3600 \mathrm{rpm}$. Flow rates maintained during scrubbing were $V_{\mathrm{A}}=490 \mathrm{~mL} / \mathrm{min}$ and $V_{\mathrm{O}}=150 \mathrm{~mL} / \mathrm{min}$. The low scrubbing $\mathrm{O} / \mathrm{A}$ ratio (relative the normal CSSX scrub ratio of 5.0) was selected as means of ensuring that adequate extract neutralization was obtained in a single contact stage.

Following scrubbing, the extract collected was moved to the organic feed position. Aqueous solutions from the scrubbing operation were collected and prepared for disposal. The 
aqueous feed and collection tanks were cleaned, and deionized water was placed into the feed tank. Water was pumped to the contactor to rinse the feed lines and the aqueous feed pump. The water in the aqueous feed tank was then replaced with approximately $4 \mathrm{~L}$ of $0.001 \mathrm{MHNO}_{3}$.

Contactor operation was initiated at $3600 \mathrm{rpm}$. Strip solution flow was started at $30 \mathrm{~mL} / \mathrm{min}$. After approximately $7 \mathrm{~min}$, aqueous flow began to exit the contactor and the solvent flow was started at a rate of $150 \mathrm{~mL} / \mathrm{min}$. Samples of effluent solutions were collected $8 \mathrm{~min}$ after starting organic-phase flow and again after 10 min of testing. As in previous testing, flows were stopped, the contactor was partially drained, and the temperature of the solution collected was measured and recorded. Flows were reestablished in the previous manner with $V_{\mathrm{A}}=60$ $\mathrm{mL} / \mathrm{min}$ and $V_{\mathrm{O}}=300 \mathrm{~mL} / \mathrm{min}$. Samples were collected at 4 and $5 \mathrm{~min}$ after the start of organicphase flow. Flows were terminated, and the temperature of the solution inside the contactor was measured and recorded.

Test results are reported in Table 5. Mass transfer efficiencies obtained under the first set of flow conditions are acceptably high. However, a significant reduction in mass transfer efficiency is indicated when the flow rates are doubled. The very limited number of data points precludes drawing any concrete conclusions regarding the loss in mass transfer efficiency.

\subsection{ADDITIONAL OBSERVATIONS}

\subsubsection{Solvent Washing in the 5-cm Contactor}

At several points during the $5-\mathrm{cm}$ contactor test effort, the solvent inventory was washed with sodium hydroxide prior to reuse. Hydraulic performance during each operation was very good over $\mathrm{O} / \mathrm{A}$ ratios ranging from 5.0 to 1.0 . While no attempt was made to determine the maximum throughput of the contactor under solvent washing conditions, it was found that washing conditions could be performed with consistent success at the same flows that were applicable to solvent stripping.

\subsubsection{Emulsion Formation}

In the process of determining flow rate maxima under stripping conditions, flow parameters were established that resulted in inadequate phase separation as evidenced by crossphase contamination of one or both effluent streams. To recover from these upset conditions, the contactor housing was drained. On every occasion, solution drained from the contactor housing when the rotor was left in operation (at $3600 \mathrm{rpm}$ ) was an emulsion with a milky, opaque appearance. Formation of the emulsion has also been reported by researchers performing 
Table 4. Single-stage extraction-mode mass transfer results using a modified centrifugal contactor

\begin{tabular}{|c|c|c|c|c|c|c|c|c|c|}
\hline $\begin{array}{l}\text { Aqueous flow } \\
(\mathrm{mL} / \mathrm{min})\end{array}$ & $\begin{array}{c}\text { Organic flow } \\
(\mathrm{mL} / \mathrm{min})\end{array}$ & $\begin{array}{l}\text { Rotor speed } \\
\quad(\mathrm{rpm})\end{array}$ & $\begin{array}{c}\text { Stage } \\
\text { temperature }\left({ }^{\circ} \mathrm{C}\right)\end{array}$ & $\begin{array}{l}\text { Aqueous } \\
\text { effluent } \mathrm{Cs} \\
\text { conc. (ppm) }\end{array}$ & $\begin{array}{l}\text { Aqueous } \\
\text { effluent } \mathrm{pH}\end{array}$ & $\begin{array}{l}\text { Organic effluent } \\
\text { Cs conc. (ppm) }\end{array}$ & $\begin{array}{c}\text { Equilibrated } \\
\text { organic phase } \\
\text { Cs conc. (ppm) }\end{array}$ & Efficiency $^{a}$ & $\mathrm{D}_{\mathrm{Cs}}$ \\
\hline 484 & 150 & 3600 & 23.8 & 1.75 & 13.58 & 39.4 & 44.1 & 88.8 & 22.5 \\
\hline 484 & 150 & 3600 & 23.8 & 1.83 & 13.63 & 38.8 & 44.7 & 86.1 & 21.2 \\
\hline 306 & 95 & 3600 & 23.5 & 1.52 & 13.63 & 40.3 & 44.4 & 90.3 & 26.5 \\
\hline 306 & 95 & 3600 & 23.5 & 1.54 & 13.63 & 39.7 & 44.9 & 87.8 & 25.8 \\
\hline
\end{tabular}

${ }^{a}$ Murphree efficiency, defined in Sect. 2.3.3.

Table 5. Single-stage stripping-mode mass transfer results using a modified centrifugal contactor

\begin{tabular}{|c|c|c|c|c|c|c|c|c|c|}
\hline $\begin{array}{l}\text { Aqueous flow } \\
\text { (mL/min) }\end{array}$ & $\begin{array}{l}\text { Organic flow } \\
(\mathrm{mL} / \mathrm{min})\end{array}$ & $\begin{array}{l}\text { Rotor speed } \\
(\mathrm{rpm})\end{array}$ & $\begin{array}{c}\text { Stage } \\
\text { temperature }\left({ }^{\circ} \mathrm{C}\right)\end{array}$ & $\begin{array}{l}\text { Aqueous } \\
\text { effluent Cs } \\
\text { conc. (ppm) }\end{array}$ & $\begin{array}{l}\text { Aqueous } \\
\text { effluent } \mathrm{pH}\end{array}$ & $\begin{array}{l}\text { Organic effluent } \\
\text { Cs conc. (ppm) }\end{array}$ & $\begin{array}{c}\text { Equilibrated } \\
\text { organic phase } \\
\text { Cs conc. (ppm) }\end{array}$ & Efficiency $^{a}$ & $\mathrm{D}_{\mathrm{Cs}}$ \\
\hline 30 & 150 & 3600 & 23.0 & 45.5 & 3.00 & 15.1 & 15.2 & 100.7 & 0.33 \\
\hline 30 & 150 & 3600 & 23.0 & 46.3 & 3.00 & 15 & 14.1 & 94.2 & 0.32 \\
\hline 60 & 300 & 3600 & 23.3 & 46 & 2.98 & 18.7 & 15 & 74.8 & 0.41 \\
\hline 60 & 300 & 3600 & 23.3 & 49.1 & 2.99 & 18.3 & 15.4 & 79.8 & 0.37 \\
\hline
\end{tabular}


concurrent CSSX testing and has been observed in stripping effluents from 2-cm contactors. To isolate the location of the emulsion in the contactor, conditions that had been found to produce an emulsion were established. After establishing steady-state operation, the housing was drained. Contactor operation was continued during draining so that the solution inventory inside the rotor was not collected. After draining the housing (i.e., the contactor mixing zone), feed flows and rotor operation were terminated and the unit was drained. The solution collected from the rotor did not contain any evidence of an emulsion.

The conclusion to be drawn from the observations reported is that the centrifugal force in the $5-\mathrm{cm}$ contactor operating under stripping conditions at $3600 \mathrm{rpm}$ is sufficient to separate the emulsion that tends to form under these conditions.

\section{CONCLUSIONS AND RECOMMENDATIONS}

Acceptable phase separation and cesium mass transfer performance are attainable under CSSX extraction and stripping conditions using a $5-\mathrm{cm}$ centrifugal contactor operated in partially pumping mode. However, the contactor throughput was found to be somewhat limited. Flow rate conditions applied in extraction testing-organic flow of $150 \mathrm{~mL} / \mathrm{min}$ and aqueous flow of $484 \mathrm{~mL} / \mathrm{min}-$-were near the limit that could be maintained for an extended period of operation. At this solvent flow rate for CSSX operation in the 5-cm contactor, our results showed that the CSSX process would stage efficiencies of $87.5 \pm 1.5 \%$ for the extraction and $97 \pm 3 \%$ for the strip section.

Limitations in equipment availability at the time of testing prevented separation of the effects of the two contactor modifications that were made to improve phase mixing. Based on prior experience with $5.5-\mathrm{cm}$ contactors, it is very likely that replacement of the vendor-supplied housing bottom plate with one having straight radial vanes (and with the appropriate gap between rotor and vanes) will improve mixing, thus permitting high stage efficiencies to be obtained using fully pumping contactors. A test program to verify this supposition should be completed before the pilot plant design is finalized. If found to be satisfactory, operation of a contactor with a conventional (straight) vane configuration in the fully pumping mode is preferable to partially pumping operation, because the former affords increased throughput flexibility, more rapid response to changes in control parameters, and faster recovery from off-normal operation.

Regardless of whether acceptable contactor performance in the fully pumping mode can be realized, there is no reason to expect that custom-designed centrifugal contactors are required for successful operation of a CSSX cascade. Instead, the reported test results indicate that a 
commercial unit with only minor modifications and with the flexibility provided by interchangeable aqueous weirs can provide the stage efficiencies needed to meet CSSX cesium removal goals. 


\section{REFERENCES}

1. P. V. Bonnesen, L. H. Delmau, B. A. Moyer, and R. A. Leonard, "A Robust Alkaline-Side CSEX Solvent Suitable for Removing Cesium from Savannah River High Level Wastes," Solvent Extr. Ion Exch. 18(6), 1079-1107 (2000).

2. D. H. Meikrantz et al., "Centrifugal Separator," U.S. Patent No. 5,762,800, June 1998.

3. R. A. Peterson, Preparation of Simulated Waste Solutions for Solvent Extraction Testing, WSRC-RP-2000-00361, Westinghouse Savannah River Company, Aiken S.C., May 2000.

4. T. R. Briggs, "Experiments on Emulsions III," J. Phys. Chem. 24, 120-126 (1920).

5. R. A. Leonard, "Design Rules for Solvent Extraction," Solvent Extr. Ion Exch. 17(3), 597-612 (1999). 


\section{INTERNAL DISTRIBUTION}

1. K. K. Anderson

2-3. J. F. Birdwell, Jr.

4. P. V. Bonnesen

5. J. L. Collins

6. R. L. Cummins

7. L. H. Delmau

8. J. N. Herndon

9. R. D. Hunt

10. R. T. Jubin

11. T. E. Kent

12-15. L. N. Klatt

16. D. D. Lec

17. M. P. Maskarinec

18. A. Mattus

19. C. P. McGinnis

20. L. E. McNeese

21. B. A. Moyer

22. K. E. Plummer

23. F. V. Sloop, Jr.

24. R. D. Spence

25. B. B. Spencer

26. J. F. Walker

27. J. S. Watson

28. ORNL Central Research Library

29. Laboratory Records, RC

30. Laboratory Records, OSTI

\section{EXTERNAL DISTRIBUTION}

31. J. T. Carter, Westinghouse Savannah River Company, P.O. Box 616, Buidling 704-3B, Aiken, SC 29808

32. D. Chamberlain, Argonne National Laboratory, Building 205, 9700 South Cass Avenue, Argonne, IL 60439

33. N. F. Chapman, Westinghouse Savannah River Company, P.O. Box 616, Buidling 704-3B, Aiken, SC 29808

34. C. Conner, Argonne National Laboratory, Building 205, 9700 South Cass Avenue, Argonne, IL 60439

35. R. G. Edwards, Westinghouse Savannah River Company, P.O. Box 616, Buidling 704-3B, Aiken, SC 29808

36. S. D. Fink, Westinghouse Savannah River Company, P.O. Box 616, Building 773-A, Aiken, SC 29808 
37. H. D. Harmon, Tank Focus Area Salt Processing Program, P.O. Box 616, Building 704-3N, Aiken, SC 29808

38. R. T. Jones, Westinghouse Savannah River Company, P.O. Box 616, Building 704-3N, Aiken, SC 29808

39. R. A. Leonard, Argonne National Laboratory, Building 205, 9700 South Cass Avenue, Argonne, IL 60439

40. J. W. McCullough, Jr., U.S. Department of Energy, Savannah River Operations Office, Bldg. 704-3N, Aiken, SC 29808

41. J. R. Noble-Dial, U.S. Department of Energy, Oak Ridge Operations Office, P.O. Box 2001, Oak Ridge, TN 37831-8620

42. Michael Norato, Westinghouse Savannah River Company, P.O. Box 616, Building 773-A, Aiken, SC 29808

43. Robert Pierce, Westinghouse Savannah River Company, P.O. Box 616, Building 773-A, Aiken, SC 29808

44. S. N. Schlahta, Tank Focus Area Salt Processing Program, P. O. Box 616, Building 704-3N, Aiken, SC 29808

45. P. C. Suggs, U.S. Department of Energy, Savannah River Operations Office, P.O. Box A, Building 704-3N, Aiken, SC 29808

46. W. L. Tamosaitis, Westinghouse Savannah River Company, P.O. Box 616, Building 773-A, Aiken, SC 29808

47. M. Thompson, Westinghouse Savannah River Company, P.O. Box 616, Building 773-A, Aiken, SC 29808

48. T. A. Todd, Idaho National Engineering \& Environmental Laboratory, Building 637, MS5218, Idaho Falls, ID 834415-5218

49. G. Vandegrift, Argonne National Laboratory, Building 205, 9700 South Cass Avenue, Argonne, IL 60439

50. Doug Walker, Westinghouse Savannah River Company, P.O. Box 616, Building 773-A, Aiken, SC 29808

51. Dennis Wester, Westinghouse Savannah River Company, P.O. Box 616, Building 773-A, Aiken, SC 29808

52. W. R. Wilmarth, Westinghouse Savannah River Company, P.O. Box 616, Building 773-A, Aiken, SC 29808

53. Tanks Focus Area Technical Team, c/o B. J. Williams, Pacific Northwest National Laboratory, P.O. Box 999, MSIN K9-69, Richland, WA 99352 
54. Tanks Focus Area Field Lead, c/o T. P. Pietrok, U.S. Department of Energy, Richland Operations Office, P.O. Box 550, K8-50, Richland, WA 99352

55. Tanks Focus Area Headquarters Program Manager, c/o K. D. Gerdes, DOE Office of Science and Technology, 19901 Germantown Rd., 1154 Cloverleaf Building, Germantown, MD 20874-1290 
